\title{
Calling for theories that test the underlying osteopathic concepts
}

In his wonderful monograph, Osteopathic Medicine: An American Reformation, George W. Northup, DO, writes, "One cannot precisely define an osteopathic lesion because mere words cannot adequately describe a whole body of observations." 1 This statement, about an entity we now know as somatic dysfunction, holds true today just as in 1966 when Dr Northup penned it.

However, it is also true that the ideas embodied in the concept of osteopathic lesion, or somatic dysfunction, must be based on the current knowledge and continually measured through scientific inquiry. In this way, this central precept of osteopathic theory can be either further explained or refuted, when appropriate.

In his own writings, Andrew Taylor Still acknowledged the importance of proper function in the maintenance of health and, conversely, the central role of improper function in the genesis of disease. During the first half of the 20th century, Louisa Burns provided solid research concerning the effects of the osteopathic lesion. In the 1940 s and 1950s, Drs Denslow, Korr, and colleagues began formulating a theory of the osteopathic lesion. This theory further explained the facilitated segment and all of the ramifications that the theory of osteopathic lesion had on the clinical observations made by osteopathic medical professionals.

Dr Korr presented a theory of the genesis of somatic dysfunction in $1975 .{ }^{2}$ His theory posited a central role for the muscle spindle proprioceptors, which gained widespread popularity in the profession. In fact, Dr Korr's theory remains an excellent example of the best of theory building in the evolution of a profession. It was presented as a testable hypothesis on how an observable entity might occur; data could either uphold or refute this hypothesis.
Unfortunately, this theory has been taken as fact at times, without careful testing. Dr Korr never meant this misuse to occur.

Now, some parts of this theory are being experimentally tested. However, as Dr Northup recognized, there are many facets to somatic dysfunction, or osteopathic lesion. As such, room exists for more than one theory of its origin and maintenance.

Beginning on page 792 of this issue, Richard L. Van Buskirk, DO, presents an intriguing new look at the way in which somatic dysfunction may occur. In his article, "Nociceptive reflexes and the somatic dysfunction: A model," Dr Van Buskirk reviews the history and some of the previous conceptual theories, including Dr Korr's proprioceptor theory. Dr Van Buskirk's own theory is based on the present knowledge of the action and effects of nociceptors. His model stems from the data available on nociception and the common characteristics of somatic dysfunction. He nicely integrates data from research performed outside of the osteopathic medical profession to constructively explain one of the osteopathic medical profession's most central theories.

In addition, Dr Van Buskirk emphasizes that his theory needs to be tested empirically. He even points out some of the testable features of his model. This type of theory building proves valuable to the profession because it increases our available testable ideas.

"Nociceptive reflexes and the somatic dysfunction: A model" should be required reading for everyone in the osteopathic profession. The presented ideas are stimulating, and the theory itself is sound. This testable theory joins other theories as possible explanations for clinical observations made by osteopathic professionals.

It is precisely because somatic dysfunction (continued on page 789) 


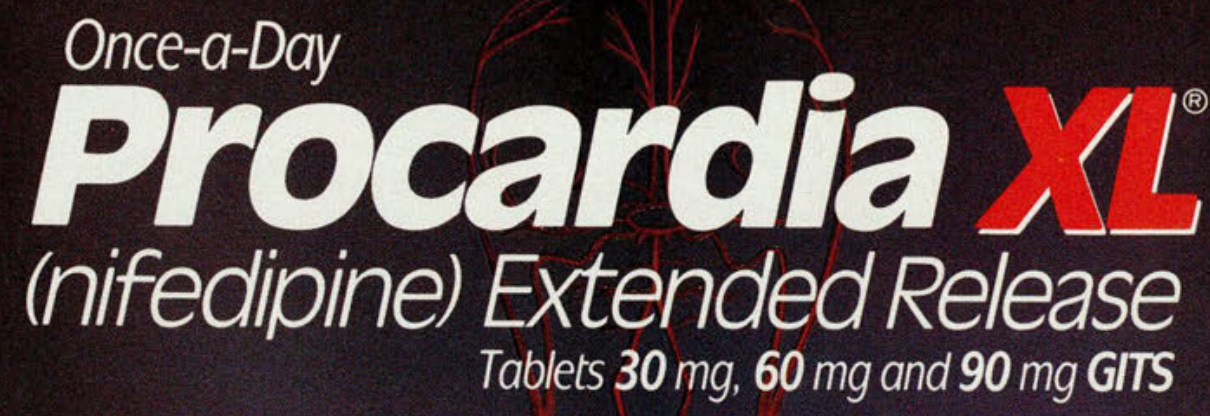




\section{THE EMERGENCE OF A SOURCE OF 24-HOUR ANTIHYPERTENSIVEAND ANTIANGINAL PROTECTION WITH ONCE-DAILY Dosing}

\section{NOW, Once-Daily Dosing Controls Hypertension}

- The only calcium channel blocker indicated for once-a-day dosing at all doses

- Effective as monotherapy' and in combination ${ }^{2}$

\section{Once-Daily Dosing Controls Angina}

- The only once-a-day calcium channel blocker for angina

- Easy to switch from nifedipine capsules to PROCARDIA XL Extended Release Tablets ${ }^{3,4}$

- PROCARDIA XL angina indications: Patients with proven or suspected vasospastic angina, and patients with classic effort angina who remain symptomatic despite adequate doses of beta blockers and/or nitrates or who cannot tolerate these agents

\section{Now, a 24-Hour Controlled-Release Delivery System}

- Releases nifedipine into the gastrointestinal tract at an essentially constant rate over the 24-hour period, independent of $\mathrm{pH}$, with no dose dumping ${ }^{5.6}$

- Minimal serum fluctuations - no significant peaks, no significant troughs $^{5}$

- Low incidence of vasodilatory side effects. The most common side effects are peripheral edema, which is not associated with fluid retention, and headache

In controlled trials of 776 patients with PROCARDIAXL,

edema resulted in discontinuation of therapy in $2.7 \%$ of patients ${ }^{4}$ 
Once-a-Day

Procardia XI

(nifedipine) Extended Release

Tablets $30 \mathrm{mg}, 60 \mathrm{mg}$ and $90 \mathrm{mg}$ GITS

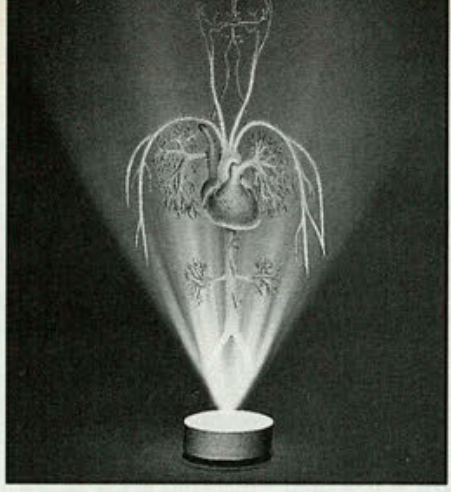

\section{4-HOUR CONTROL FOR BOTH HYPERTENSION AND ANGINA WITH ONCE-DAILY DOSING}

\section{EASY TO INITIATE ONCE-DAILY DOSING}

- Initiate once-a-day therapy with a single 30-mg or 60-mg PROCARDIA XL Extended Release Tablet, swallowed whole

\section{EASY TO SWITCH TO ONCE-DAILY DOSING}

- Over $90 \%$ of angina patients controlled on nifedipine capsules were easily switched and controlled on PROCARDIA XL Extended Release Tablets at the nearest equivalent total daily dose; others needed dosage adjustment ${ }^{4}$

\section{TITRATION SHOULD PROCEED AS CLINICALLYWARRANTED}

\section{- For full dosage instructions, see prescribing information}

References: 1. Gavras I. Mulinari R. Gavras H. et al: Antihypertensive effectiveness of the nifedipine gastrointestinal therapeutic system. Am J Med 1987:83(suppl 6B): 20-23. 2. Frishman WH Garofalo JL. Rothschild A, et al: The nifedipine gastrointestinal therapeutic system in the treatment of hypertension. Am J Cardiol 1989:64(suppl to No. 11):65F-69F. 3. Vetrovec GW. Parker VE,

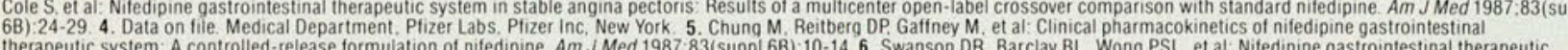
therapeutic system: A controlled-release formulation of nifedipine. Am J Med 1987:83(suppl 6B):10-14. 6. Swanson DR, Barclay BL. Wong PSL. et al: Nifedipine gastrointestinal therapeutic system. Am J Med 1987;83(suppl 6B):3-9.
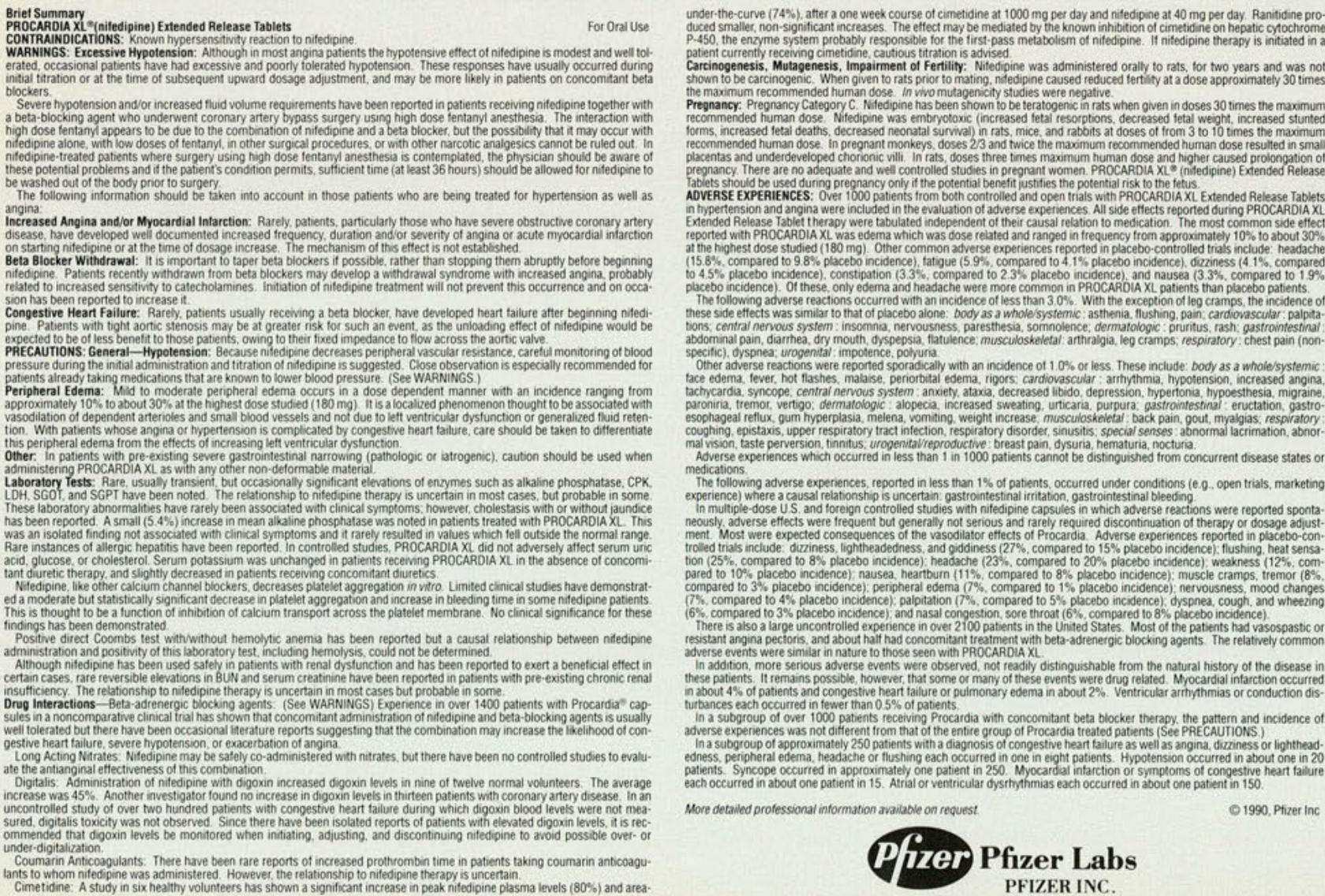
may have more than one initiating, perpetuating mechanism that we are sorely in need of more testable theories such as the one Dr Van Buskirk proposes. Future theories should integrate the vast amount of structural and functional knowledge obtained from laboratories, both within and outside of the profession, into the central concepts of osteopathic medicine. Indeed, if we believe that the concepts of osteopathic medicine are universal and important, then we must reach out to interpret the data in light of the osteopathic philosophy. No one will do it for us.

MICHAEL M. PATTERSON, PhD

Contributing Editor

\footnotetext{
1. Northup GW: Osteopathic Medicine: An American Reformation, ed 2. Chicago, Ill, American Osteopathic Association, 1979, p 47

2. Korr IM: Proprioceptors and somatic dysfunction. JAOA 1975;74:638650
}

\section{Just what is osteopathic medicine's role in society?}

"What health needs does the osteopathic medical profession purport to meet that are not being met, or likely to be met, by any other profession?"-Irvin M. Korr, $\mathrm{PhD}$

In a recent editorial (JAOA 1990;90:128), I opined that our role in society remains greatly misunderstood, not only by the public, but by many persons in the osteopathic medical profession as well. Osteopathic medicine's boundless potential still remains shackled by a lack of clarity as to its real distinction, its role, and its function in society.

Dr Korr eloquently examines this dilemma in his article, "Osteopathic medicine: The profession's role in society," beginning on page 824. He addresses how we osteopathic physi- cians can use our education skills and philosophy to enhance the prevention of chronic disease in society.

"When osteopathic physicians who are skilled in OMT are also able, themselves or in collaboration with others, to provide guidance for their patients in behavioral, psychosocial, and nutritional realms, they have command of a powerful lever for moving the whole person, and not just a part of the body."

Dr Korr acknowledges, as we osteopathic physicians should, that we have always had the knowledge and skills necessary for maintaining health in our patients: "Having, from its beginning, emphasized in its practice the inherent health-maintaining and the healthrestoring powers, the osteopathic medical profession has long had the opportunity to lead this movement."

I am certain that you, our readers, will agree that Dr Korr's ideas make a seminal contribution to our understanding of the role of osteopathic medicine in addressing society's healthcare needs. The JAOA welcomes and encourages your response and comments.

THOMAS WESLEY ALLEN, DO Editor in Chief

\section{Making the most of growing older}

The aging generation is enjoying a degree of popularity-almost. I have no trouble belonging, for my credentials are more than adequate. Sometimes they are more adequate than others, but adequate nonetheless.

Robert Browning said it well when he wrote:

I'm growing fonder of my staff; I'm growing dimmer in the eyes; I'm growing fainter in my laughs; I'm growing deeper in my sighs; I'm growing careless of my dress;

(continued on page 790) 